\title{
PRELIMINARY ASSESSMENT OF EXPERIMENTAL SOPHOMORE EE COURSES
}

\author{
James G. Harris and Kena Burke
}

\begin{abstract}
In academic year 2001-2002. an experimental yearlong sequence of courses was taught to $E E$ and $C P E$ majors that replaced the traditional circuits and electronics sequence of required courses. The experimental sequence consisted of three quarters, with the first quarter devoted to digital signal processing, and the next two quarters formed from an integrated approach to circuits and electronics. The two sections of students who took the experimental course now are taking the junior year required courses in their major. An assessment is being made to compare the experimental students with a cohort of traditional students. Preliminary results are given for retention rates and for their respective performance in the required junior year courses.
\end{abstract}

Index Terms - Electrical Engineering curriculum, assessment, DSP first, integrated circuits and electronics

\section{INTRODUCTION}

Two emerging curricula trends within the lower division introductory courses for the Electrical and Computer Engineering Curriculum are the introduction of digital signal processing before the traditional circuits course, and the integration of electronics with the first courses in circuits. These wo trends were incorporated into an experimental three-quarter-sophomore sequence of four-unit courses at Cal Poly in the 2001-2 academic year that replaced 14 units of traditional circuits and electronics courses. The courses were taught in studio format within two-hour blocks meeting three times a week. The first course was based upon the textbook DSP First [1] and the course at Georgia Tech. The second and third quarters used the same textbooks for circuits [2] and electronics [3] as used by the traditional students, but used an integrated approach. The faculty allowed the experimental courses to satisfy the prerequisites for the junior year courses.

\section{Assessment Procedure}

The preliminary assessment of this experiment compares the retention rates, i.e., how many students failed courses, and compares the performance in the junior year of the experimental students with the traditional students. The cohort group was determined from traditional students who entered the junior year at the same time (Fall 2002) by matching them to a histogram of Cal Poly GPAs of the experimental students in the quarter before the experimental sequence began (Spring 2001). The mean and standard deviations of the grades for each group of students are used.

\section{Preliminary Assessment Results}

There were 55 students who enrolled in the first two sections of the sequence. Ten students did not enroll in the second course: only four did failing work (they were given a grade of $\mathrm{C}$ after enrolling back into the traditional sequence). The other six chose not to continue, but had grades of $\mathrm{C}$ or greater and returned to the traditional sequence. One student dropped out to accepted a co-op in the Spring 2002 quarter. Four students in the last course did not pass, and were required to take the last circuits and first electronics courses in the traditional sequence. Thus, there were a total of eight students out of 55 (or 15\%) who did not pass. Typical retention rates for the traditional sequence of courses is on the order of $20-25 \%$ not passing. Table I compares the performance of the two groups of students in the required junior year courses; it is incomplete at this time.

TABLE 1

COMPARISON OF EXPERIMENTAL AND TRADITIONAL GRADES

\begin{tabular}{lllllll}
\multicolumn{1}{c}{ COMPARISON OF EXPERIMENTAL AND TRADITIONAL GRADES } \\
\hline Course & Cnt & Mean & Sgma & Cnt & Mean & Sgma \\
EE301 & 34 & 2.75 & 0.96 & 44 & 2.50 & 1.18 \\
EE341(I) & 34 & 2.85 & 0.68 & 39 & 2.71 & 0.80 \\
EE307 & 35 & 2.51 & 0.90 & 38 & 2.39 & 1.14 \\
EE347(1) & 36 & 3.27 & 0.71 & 38 & 3.03 & 0.75 \\
EE325 & 23 & 2.69 & 0.84 & 26 & 2.69 & 0.93 \\
EE365(1) & 23 & 3.66 & 0.54 & 26 & 3.28 & 0.71 \\
EE302 & 16 & 3.06 & 0.78 & 26 & 2.61 & 0.71 \\
EE342(1) & 16 & 3.43 & 0.61 & 27 & 3.13 & 0.74 \\
EE304 & 17 & 3.21 & 0.57 & 17 & 2.84 & 0.95 \\
EE308 & 14 & 3.36 & 0.38 & 17 & 3.21 & 3.52 \\
EE348(I) & 13 & 3.33 & 0.45 & 17 & 2.66 & 0.78 \\
EE 328 & 8 & 3.13 & 0.51 & 15 & 2.52 & 1.00 \\
EE 334 & 6 & 3.27 & 0.32 & 14 & 2.54 & 0.81 \\
\hline
\end{tabular}

\section{CONCLUSIONS}

It appears that the experimental students have not been harmed. Further, a case could be made the experimental students are performing better that the traditional students.

\section{REFERENCES}

[1] McClellan, J. H., Schafer, R. W., Yoder; M. A.; DSP FIRST:A Multimedia Approach; Prentice Hall; 1999

[2] Alexander,C. K., Sadiku, M. N. O.; Fundamentals of Electric Circuits; McGraw-Hill; 2000

[3] Jaeger, R. C., Microelectronic Circuit Design; McGraw-Hill; 1997 